\title{
Development of the surface displacement velocity in a full-scale loamy model slope under multistep excavation
}

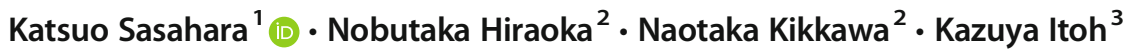

Received: 13 December 2020 / Accepted: 27 March 2021 / Published online: 24 April 2021

(C) The Author(s) 2021

\begin{abstract}
Multistep excavations were implemented at the toe of a large-scale slope model, and the surface displacements in the slope were measured to examine the validity of the relationship between the velocity and acceleration proposed by Fukuzono for excavated slopes. The surface displacement increased both during and after slope excavation, among which the latter was due to creep deformation under a constant stress. The rate of increase in the surface displacement was initially high and then decreased to zero during creep deformation after the excavation without slope failure. However, the surface displacement exhibited an accelerated increase during creep deformation after the final excavation prior to slope failure; the surface displacement increased with small fluctuations even before slope failure occurred. The surface displacement velocity and acceleration also fluctuated notably due to variations in the surface displacement. The trendlines for the derived relationships between the velocity and acceleration were in good general agreement with the measured data at certain locations in the model slope. These relationships were unique at different locations on the slope, while the inclination of the relationship trendline suddenly decreased just prior to slope failure. The steeper trendlines predicted an earlier failure time if the displacement was large and close to the failure condition, whereas they resulted in worse predictions if the displacement was small and far from causing slope failure according to the prediction method proposed by Fukuzono.
\end{abstract}

Keywords Model slope $\cdot$ Failure $\cdot$ Excavation $\cdot$ Displacement $\cdot$ Velocity $\cdot$ Acceleration

\section{Introduction}

The measurement of the displacement or deformation of a slope is expected to be an effective early warning tool against landslides. Researchers reported an accelerated increase in the displacement of the surface of a slope just prior to failure. Kromer et al. (2015) and Carlà et al. (2019) monitored the time variation of the topography of rock walls by light detection and ranging (LiDAR) and ground-based synthetic aperture radar interferometry (GBInSAR), respectively, prior to slope failure. Analyses of the displacements of targets on

Katsuo Sasahara

sasahara@kochi-u.ac.jp

1 Natural Science Cluster, Kochi University, 2-5-1, Akebonocho, Kochi, Kochi 780-8520, Japan

2 National Institute of Occupational Safety and Health, Tokyo, Japan

3 Faculty of Architecture and Urban Design, Tokyo City University, Tokyo, Japan walls revealed an accelerated increase in the displacement of the targets. Loew et al. (2017) measured the accelerative increase of the width of cracks located at the head scarp of the landslide and tried to predict failure time based on the measurement. Askarinejad et al. (2018) sprinkled water on a natural soil slope and measured the soil-water conditions and deformation before the failure of the slope. The acceleration of the soil layer deformation and horizontal earth pressure was measured by soil deformation sensors and earth pressure cells, respectively, just before slope failure. These facts suggested that an accelerated increase in the displacement or deformation of a soil and rock slope occurred just prior to failure. Xie et al. (2020) measured the movement of model slopes and small-scale natural slope by sophisticated tilt sensor with microelectromechanical systems (MEMS) and reported accelerated increase of the tilting of the sensor. They also reported the inverse velocity approached zero with increasing time just prior to failure.

The acceleration of the displacement and deformation of a slope was modelled, and the models were applied by many researchers to predict the failure time of a slope. The 
acceleration of the displacement was originally found at the tertiary creep stage under constant-stress conditions (Fig. 1), while it was observed in slopes under various stress conditions, such as rainfall. Researchers adopted the inverse velocity of the displacement for the prediction of the failure time, and this was based on a linear relationship between the velocity and acceleration on a logarithmic scale (Bozzano et al. 2011; Mazzanti et al. 2015; Crosta and Agliardi 2003; Fukuzono 1985; Varns 1982; Voight 1988; Voight 1989). Fukuzono (1985) found a relationship for the model slopes under the sprinkling of water. Fukuzono (1985) proposed the relationship based on the measurement of the surface displacement on model slopes under sprinkling water as follows:

$\frac{d v}{d t}=a \cdot v^{\alpha}$

where $v$ and $t$ are the velocity and time, respectively. $a$ and $\alpha$ are experimental constants. It can be recognized that $a$ and $\alpha$ represent an intercept on the vertical axis and a gradient of a line for the relationship, respectively. Constants $a$ and $\alpha$ can be derived by the regression analysis of the relation between the velocity and acceleration based on the measured displacement on the slope. Integration of Eq. (1) produces Eq. (2) for the relationship between the time $(t)$ and velocity $(v)$ as follows:

$v=\{a(\alpha-1)\}^{\frac{1}{1-\alpha}}\left(t_{\mathrm{r}}-t\right)^{\frac{1}{1-\alpha}}(\alpha>1)$

Rearrangement of Eq. (2) produces an equation for deriving the failure time $\left(t_{\mathrm{r}}\right)$ of the slope as follows:

$t_{\mathrm{r}}=\frac{v^{1-\alpha}}{a(\alpha-1)}+t$

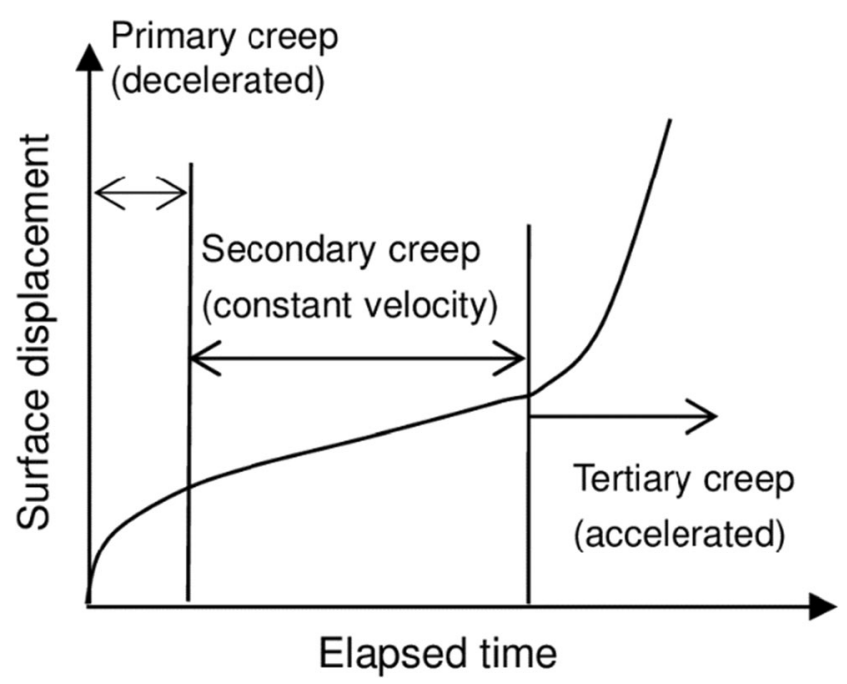

Fig. 1 Time variation of the soil displacement under constant-stress conditions
The equation indicates that $a$ and $\alpha$ have a large influence on the failure time $\left(t_{\mathrm{r}}\right)$. In particular, $\alpha$ has a larger influence because it is a power number. Constants $a$ and $\alpha$ can be determined based on the relationship between the velocity and acceleration on a logarithmic scale. He proposed prediction method of failure time, namely inverse-velocity method. This is based on the relationship between time and inverse-velocity derived from Eq. (2). Bozzano et al. (2011), Mazzanti et al. (2015) and Crosta and Agliardi (2003) obtained creep deformation relationships for large-scale rock slopes. Federico et al. (2012) introduced a linear correlation between the logarithm of peak velocity and that of peak displacement acceleration, and Carlà et al. (2017) further developed his work on the linear correlation between peak velocity and peak acceleration on a nonlogarithmic scale. These results suggested that the relationship between the velocity and acceleration could be applied to slopes of various scales and materials under different stress conditions. Varns (1982) and Voight $(1988,1989)$ showed that the relationship could be verified not only at various shear phenomenon scales from small rock specimens for indoor shear tests to large-scale rock slopes but also for various materials such as soil, rock, concrete and steel. They considered many studies related to the shear failure of various materials and analysed the relationships between the velocity and acceleration. The stress conditions at the time of failure of the above materials varied in the literature. Some slopes deformed and failed due to the increase in the pore pressure according to rainfall infiltration, while other materials deformed under constant-stress conditions. The validity of the relationship remains unclear because of the insufficient examination of the stress conditions in the literature. The conditions for the relationship should be validated to utilize it to predict slope failure. In particular, the validity of the relationship was scarcely examined for the excavation of a slope, even though studies reported an accelerated increase in the displacement prior to the failure of open-pit mine walls under multistep excavation (Voight and Kennedy 1979). Other modelling studies on the velocity relied on the relationship between the time to failure and strain rate (Saito 1965; Saito and Yamada 1973) and the Sshaped curve for the time variation of the displacement prior to failure (Xiao et al. 2009). The former was categorized as one of the expressions of the Fukuzono relationship by Varns (1982), while the latter was comparable to the inverse velocity of the displacement for directly expressing the accelerated increase in the displacement. Hao et al. $(2016,2017)$ proposed the utilization of the ratio of the velocity to the acceleration. The ratio 
approached zero with increasing time. This idea was a similar method based on the linear correlation between the velocity and acceleration. The conditions for the relationship between the velocity and acceleration should be validated for these methods.

Certain reports described the surface displacement prior to the failure of slopes under excavation or cutting (Voight and Kennedy 1979: Rigby and Carr 1987: Bozzano et al. 2011: Mazzanti et al. 2015). Voight and Kennedy (1979) reported the displacement of the surface of an open-pit wall under excavation and blasting in Chile. Mining activities continued until February 16, 1969, with increasing displacement, and the slope failed on February 18, 1969. The displacement notably increased starting in November 1968 and then revealed an accelerated increase. Earthquakes might have also influenced the instability of the slope. Rigby and Carr (1987) analysed the instability of an excavated slope in a coal-pit mine. The slope was excavated at an inclination of 1/2.5 in September 1985, and displacement was measured until failure (121 days). The displacement greatly increased with rainfall and finally exhibited an accelerated increase up to failure. Bozzano et al. (2011) and Mazzanti et al. (2015) reported displacement measurements on slopes affected by excavation for the construction of roads and tunnels. They found large displacements after substantial rainfall and small landslides of the studied slopes. The displacement was measured by GBInSAR. They reported an accelerated increase in the displacement prior to failure and tried to predict the failure time by the inverse-velocity method to improve the method. Tamate and Hori (2018) reported the results of monitoring the deformation of a shallow surface layer in a model slope under excavation by a pipe strain meter and observed an accelerated increase in the deformation of the layer prior to slope failure. Zhou et al. (2020) and Zhou and Ye (2021) reported the accelerating increase of the displacements on the slopes excavated for coal and copper mining. They implemented to predict a failure time of the slopes by the inversevelocity method and tried to improve the method. These studies reported accelerated increases in the displacement prior to slope failure, but they did not examine the relationship between the velocity and acceleration in detail during or just after excavation. The relationship between the velocity and acceleration should be examined in a slope under excavation because it is the basis of prediction method such as the inverse-velocity method. The prediction cannot be corrected if the relationship between the velocity and acceleration cannot be established.

Multistep excavation in a large-scale slope model was implemented to measure the displacement of the surface of a slope in this study. Measured data were analysed to examine the effect of excavation on the displacement, and the relationship between the velocity and acceleration based on the work by Fukuzono (1985) was adopted in this paper to validate the application of this relationship to predict the slope failure time. Novel prediction method of failure time was proposed directly based on the relationship between the velocity and acceleration.

\section{Methodology}

\section{Model slope and measurement devices for the slope displacement}

Figures $2 \mathrm{a}$ and $\mathrm{b}$ show plane and lateral views of the model slope and locations of the measurement devices, respectively. The model slope was constructed to simulate the excavation of a full-scale slope made of failed soil for the elimination of road landslides in the Large-Scale Model Testing Laboratory, National Institute of Occupational Safety and Health, Japan. Figure 3 shows a frontal view of the slope with the installed measurement devices. The model slope was $3.5 \mathrm{~m}$ high and $4 \mathrm{~m}$ wide, and the slope surface inclination was $30^{\circ}$ with a horizontal crest of $1.7 \mathrm{~m}$ above the slope. The scale of the model slope was decided on the fact that most of the accidents of workers due to being buried by falling soil mass occurred during excavation of the slope less than $5 \mathrm{~m}$ high in Japan. The model was constructed of loamy soil, and its physical properties are provided in Table 1. The model slope was built up and divided into seven $50-\mathrm{cm}$ layers containing 1 layer with a bulk density of $1.0 \mathrm{~g} / \mathrm{cm}^{3}$. The soil layer of $1.0 \mathrm{~g} / \mathrm{cm}^{3}$ was very loose and was constructed without layer compaction. This is supposed to be a failed soil mass deposited at the foot of the collapsed slope made of loamy soil in Japan. The density of undisturbed loamy soil is often less than $1.0 \mathrm{~g} / \mathrm{cm}^{3}$ in Japan. Four undisturbed specimens were collected from the surface of each layer after construction to measure the water content and density of the soil. The wet density, dry density, and water content of the soil ranged from $0.983 \sim 1.023 \mathrm{~g} / \mathrm{cm}^{3}(0.983 \mathrm{~g} /$ $\mathrm{cm}^{3}$ on average), $0.511 \sim 0.552 \mathrm{~g} / \mathrm{cm}^{3}\left(0.528 \mathrm{~g} / \mathrm{cm}^{3}\right.$ on average), and $87.16 \sim 90.6 \%$ ( $88.66 \%$ on average), respectively.

Table 1 Physical properties of the soil of the model slope

\begin{tabular}{ll}
\hline Specific gravity of soil mineral $\left(\rho_{\mathrm{s}}, \mathrm{g} / \mathrm{cm}^{3}\right)$ & 2.759 \\
Grain size distribution & \\
Sand $(0.075-2 \mathrm{~mm})(\%)$ & 6.2 \\
Silt $(0.005-0.075 \mathrm{~mm})(\%)$ & 45.3 \\
Clay (less than $0.005 \mathrm{~mm})(\%)$ & 48.5 \\
Liquid limit $\left(W_{\mathrm{L}}, \%\right)$ & 158.3 \\
Plasticity limit $(\%)$ & 97.7 \\
Plastic index $\left(I_{\mathrm{P}}\right)$ & 60.6 \\
Maximum dry density $\left(\rho_{\mathrm{dmax}}, \mathrm{g} / \mathrm{cm}^{3}\right)$ & 0.665 \\
Optimum moisture content $(\%)$ & 102 \\
\hline
\end{tabular}




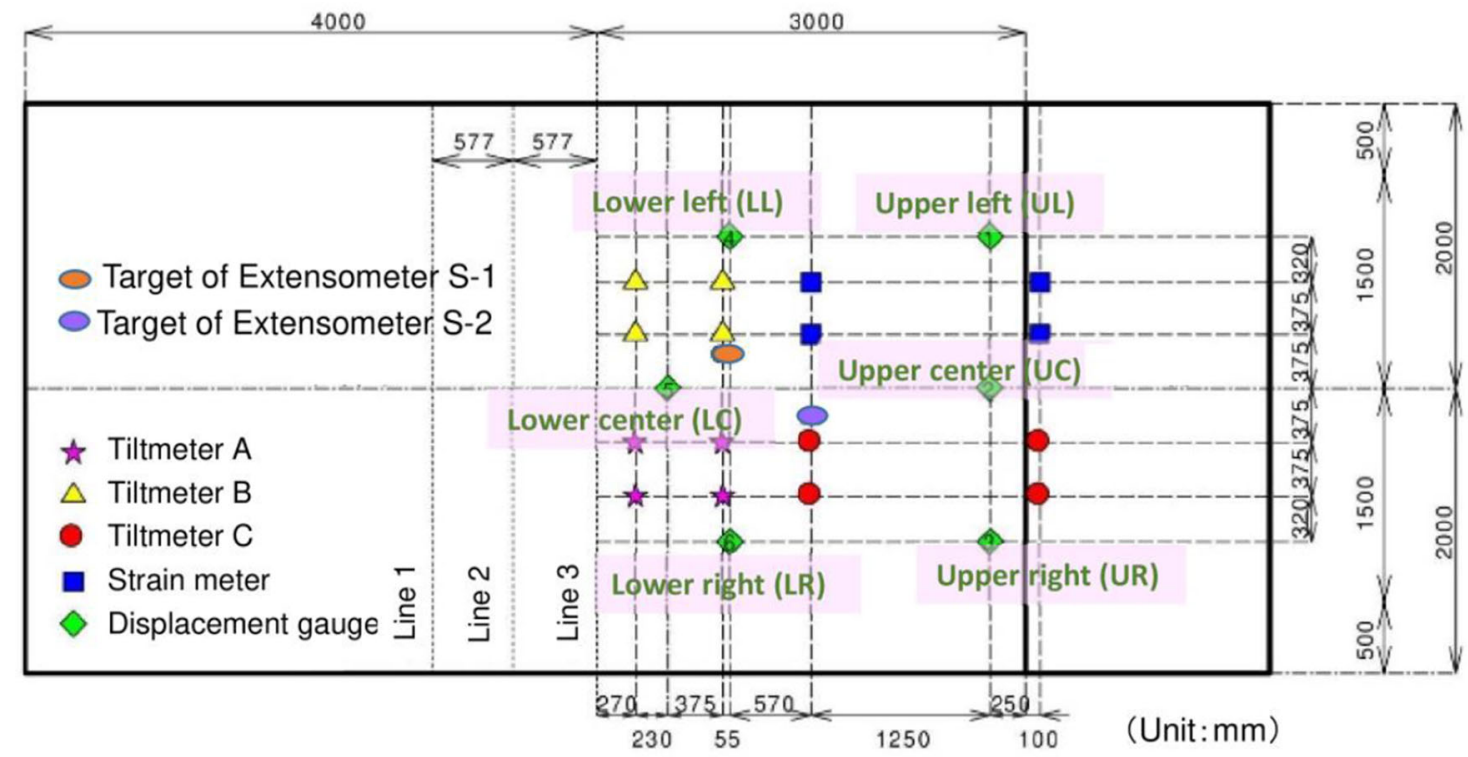

(a)

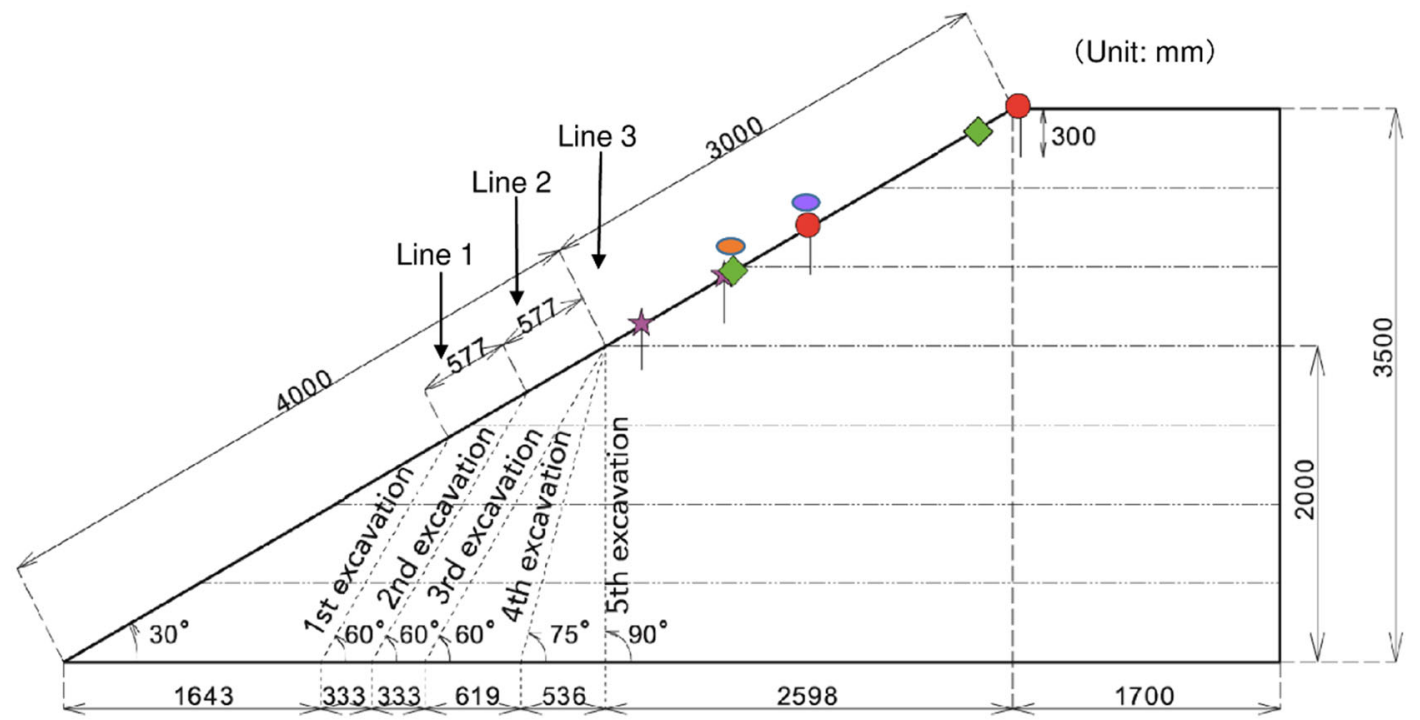

(b)

Fig. 2 Model slope and arrangement of the devices for the measurement of the displacement. a Plan view. b Lateral view

The moisture content of the soil was almost the same as the optimum water content, while the dry density was lower than the maximum dry density. This demonstrated that the soil was loose and wet. The lateral sides of the slope were lubricated with vinyl sheets against the concrete walls.

Extensometers, displacement gauges, and tiltmeters were installed on the surface of the slope to measure the slope displacement. The upper ends of the extensometers were fixed on the wall of the building of the laboratory. The resolution of the extensometers was $0.01 \mathrm{~mm}$. The displacement gauges parallel and vertical to the surface of the slope were set to a certain target, as shown in Fig. 4. The displacement gauges were fixed on steel pipes on the model, as shown in Fig. 3, while a target was placed on the surface of the model with spikes to prevent slippage. The resolutions of the displacement gauges were not the same but ranged from 0.01 to $0.033 \mathrm{~mm}$ because the gauges had different full scales such that the data were selected to be within $0.05 \mathrm{~mm}$ of the difference in the measured displacement. The displacement parallel to the surface (referred to as the surface displacement 


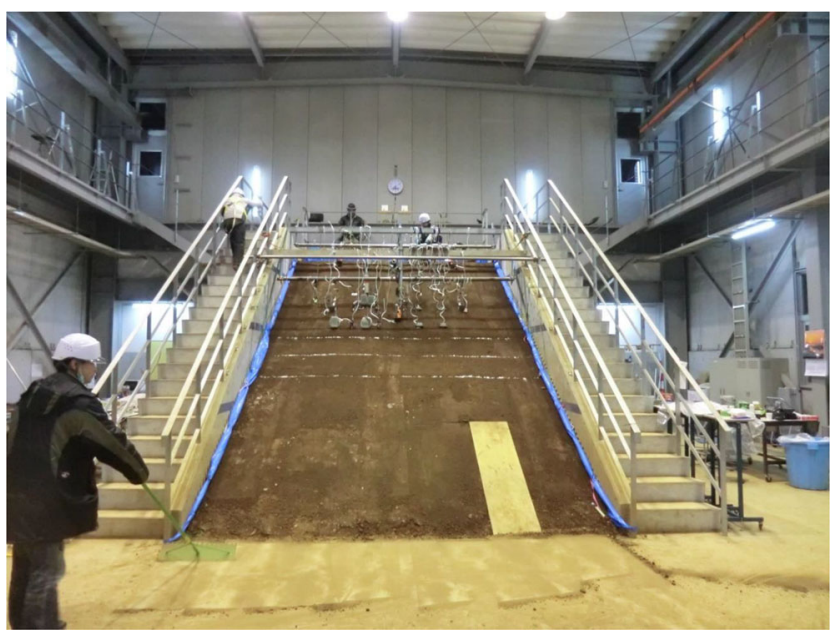

Fig. 3 Frontal view of the model slope

hereafter) was defined to be positive when the gauge target moved downward, while the displacement vertical to the surface (referred to as the vertical displacement hereafter) was defined to be positive when the target moved vertically downward relative to the surface. The surface displacements at the lower left (LL), lower centre (LC), lower right (LR), upper left (UL), upper centre (UC) and upper right (UR) were adopted for the analysis in this paper. The surface displacements at the LL, LC and LR were categorized as those at the lower part of the slope, while those at the UL, UC and UR were categorized as those at the upper part of the slope.

\section{Experimental conditions}

The duration and condition of each excavation step are listed in Table 2. Eight excavation steps were conducted with longitudinal sections after each step, as shown in Figs. $2 \mathrm{~b}$ and 5. The process simulated the actual case of the excavation of failed soil below the collapsed slope; thus, the model slope was excavated with a gentler slope than the angle of repose of the soil (usually $30^{\circ}$ ) step by step. The 1 st to 3 rd excavations were conducted from lines 1 to 3 on the surface of the slope

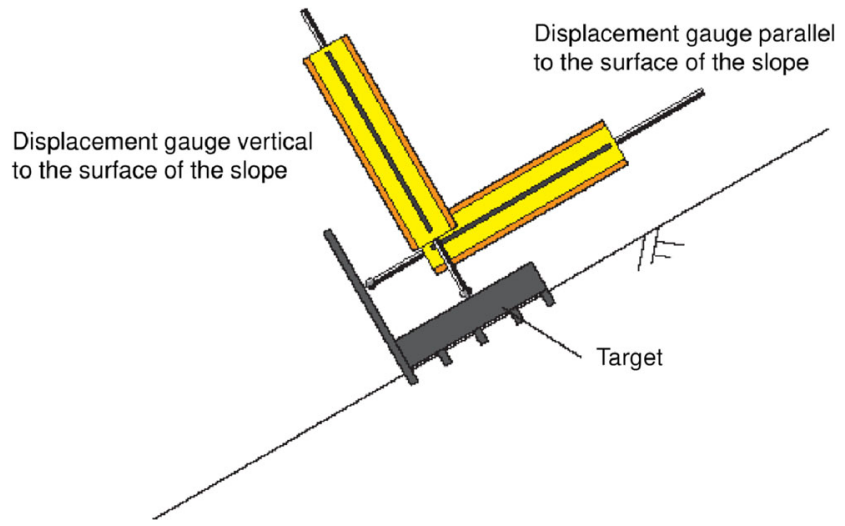

Fig. 4 Measurement of the displacements parallel and vertical to the surface of the model slope along a $60^{\circ}$ inclined plane to the toe of the slope, as shown in Figs. $2 \mathrm{~b}$ and $5 \mathrm{a}$. The 4 th and 5 th excavations were conducted from line 3 along a $75^{\circ}$ inclined plane and along a vertical inclined plane to the toe of the slope, respectively. The excavated plane failed during the 5 th excavation. The deposited soil mass of the failure during the 5 th excavation was excavated during the 6th to 8th excavations, as shown in Fig. 5b. The centre, left and right parts of the slope were excavated with the bucket of a hydraulic excavator for a step of the excavation because the width of the bucket was $1.8 \mathrm{~m}$, which was smaller than the width of the slope $(4 \mathrm{~m})$. Although the procedure of excavation in lateral direction might affect the failure time of the model slope, it was out of scope in this experiment.

\section{Velocity and acceleration}

The velocity and acceleration were derived following the procedure. The velocity was defined as the difference in the surface displacement between the previous and present time steps divided by the difference between these time steps. The increases in the surface displacement and time were derived as $\left(s d_{i}-s d_{i-1}\right)$ and $\left(t_{i}-t_{i-1}\right)$, respectively. Dividing $\left(s d_{i}-s d-\right.$ $\left.i_{-1}\right)$ by $\left(t_{i}-t_{i-1}\right)$ produced the velocity $v_{i-0.5}$ corresponding to the time of $t_{i-0.5}=\left(t_{i}-t_{i-1}\right) / 2$. Here, time step $i, i-1$ and $i+1$ indicate present time, the time of one step before present time and the time of one step after present time, respectively.

The acceleration was defined as the difference in the velocity between the previous and present time steps divided by the difference between these time steps. The acceleration $(v / d t)_{i}$ was derived from two velocities $v_{i-1.5}$ and $v_{i-0.5}$. Thus, three surface displacements were required, namely $s d_{i-2}, s d_{i-1}$ and $s d_{i}$.

\section{Results of the experiment}

\section{Slip surface after excavation and failure}

Frontal views of the model slope after the failure during the 5th excavation and the final failure are shown in Fig. 6a and b, respectively. The slip surface in Fig. 6a seems to be slightly concave in the cross section of the slope, which indicates that friction along the lateral boundary disturbed the slope failure to a certain extent. The final failure generated a plane slip surface, as shown in Fig. 6b, which implies that the failure was not affected by the friction along the lateral boundary. Three digging steps for one excavation seemingly did not yield a nonuniform cross section of the slip surface.

Longitudinal sections of the slip surface after each excavation and failure are shown in Fig. 5. The slip surface was inclined $60^{\circ}$ downslope from $1 \mathrm{~m}$ above line 3 on the surface and then proceeded parallel to the original surface at $1 \mathrm{~m}$ deep 
Table 2 Time of the excavations and failures

\begin{tabular}{|c|c|c|c|}
\hline & $\begin{array}{l}\text { Tim of start } \\
\text { (s) }\end{array}$ & $\begin{array}{l}\text { Time of finish } \\
\text { (s) }\end{array}$ & Condition of excavation and failure \\
\hline $\begin{array}{l}\text { Start of } \\
\text { measurement }\end{array}$ & 0 & & \\
\hline 1st excavation & 600 & 1320 & $60^{\circ}$ inclined to the toe from line 1 \\
\hline 2nd excavation & 2400 & 2950 & $60^{\circ}$ inclined to the toe from line 2 \\
\hline 3rd excavation & 4200 & 4880 & $60^{\circ}$ inclined to the toe from line 3 \\
\hline 4th excavation & 7800 & 8560 & $60^{\circ}$ inclined to the toe from line 3 \\
\hline 5th excavation & 13,230 & 13,560 & $\begin{array}{l}\text { Vertical at line } 3 \\
\text { Excavated face collapsed during the excavation }\end{array}$ \\
\hline 6th excavation & 16,680 & 17,040 & $\begin{array}{l}\text { Failed soil was excavated at a } 38^{\circ} \text { inclination from the } \\
\text { surface }\end{array}$ \\
\hline \multirow[t]{3}{*}{ 7th excavation } & 18,480 & 19,290 & $\begin{array}{l}2 \text { stages of excavation with a } 60^{\circ} \text { inclination from the } \\
\text { surface }\end{array}$ \\
\hline & 19,380 & 19,800 & \\
\hline & & & Left part of the excavated face collapsed \\
\hline 8th excavation & 22,260 & 22,950 & $\begin{array}{l}\text { Toe of the failed soil excavated vertically from the } \\
\text { surface }\end{array}$ \\
\hline Final failure & 23,387 & & \\
\hline
\end{tabular}

after the 5th excavation, as shown in Fig. 5a. The collapse of the left part of the excavated face during the 7 th excavation was so small that it did not influence the shape of the longitudinal section. The slip surface was inclined $60^{\circ}$ downslope
Fig. 5 Longitudinal sections of the slope after the excavations and failures. a From the initial excavation to the 5 th excavation. b From the 5th excavation to the final excavation

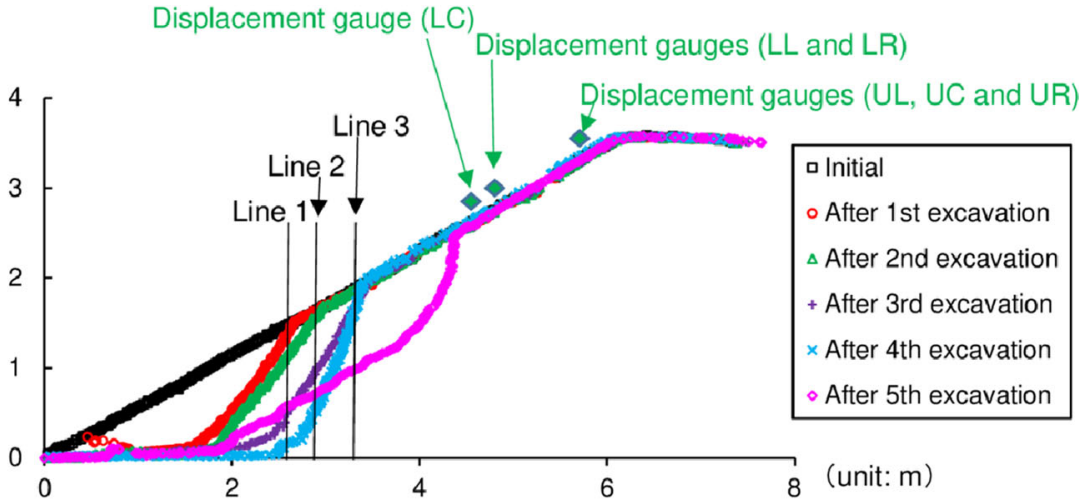

(a)

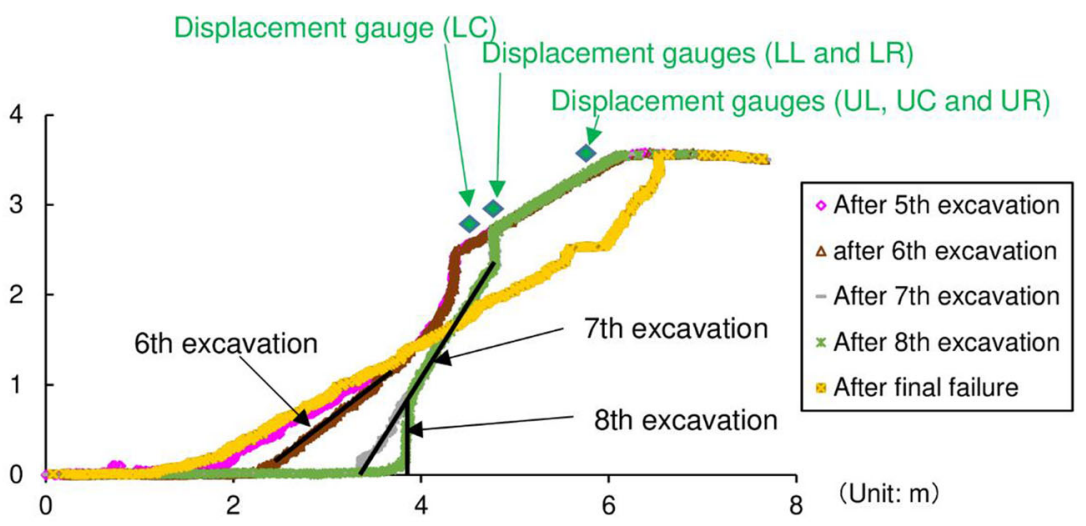

(b) 


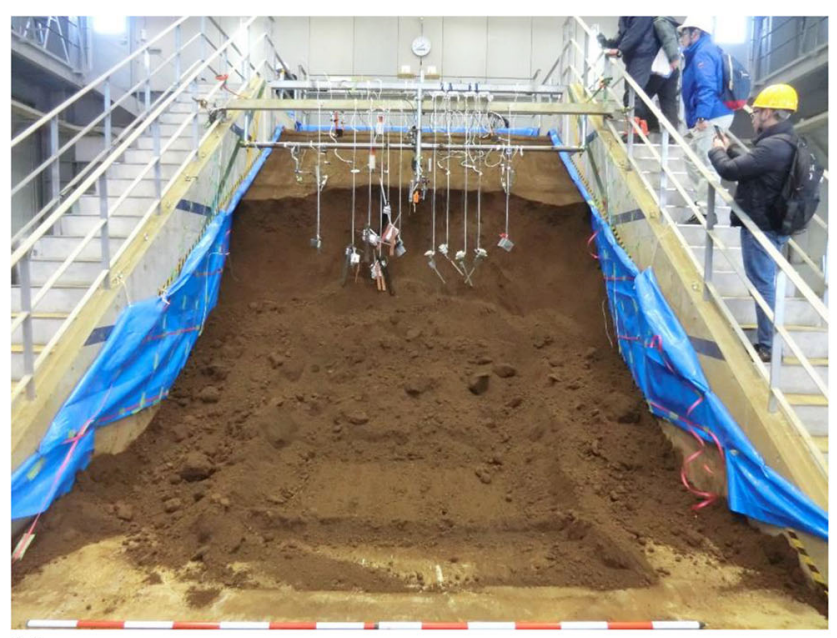

(a)

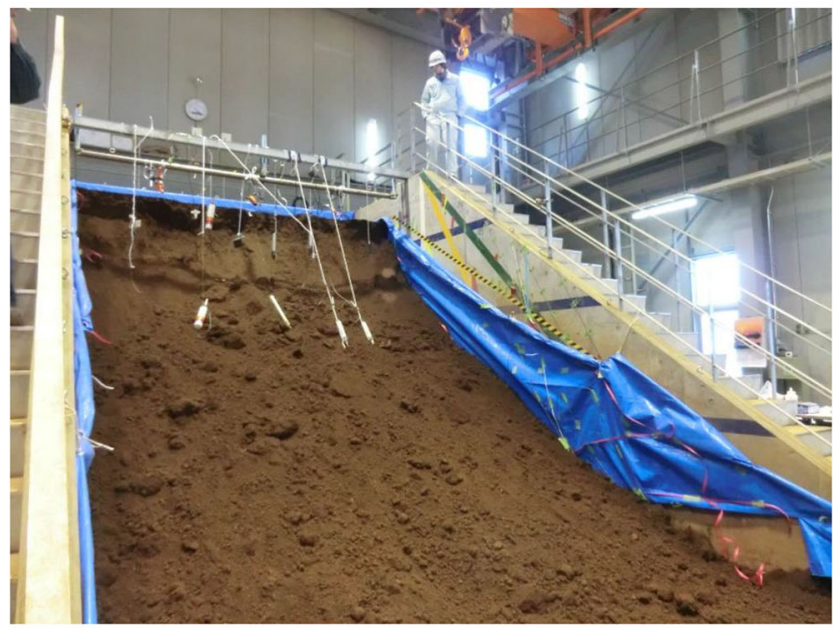

(b)

Fig. 6 Frontal view of the model slope after failure of the slope. a After failure during the 5 th excavation. b After final failure

from $0.5 \mathrm{~m}$ behind the edge of the crest and then proceeded parallel to the original surface at $1 \mathrm{~m}$ deep after the final failure (Fig. 5b). The lower part of the slip surface became connected to the surface of the deposited soil, which was also parallel to the original surface.

\section{Time variation of the surface displacement}

The time variation of the surface displacement is shown in Fig. 7. The surface displacement at the lower part of the slope (LL, LC and LR) did not exhibit a notable increase before the 3rd excavation. The displacement greatly increased from the start of the 3rd excavation and then continued to increase after the 3rd excavation. The displacement also increased during the 4th excavation and thereafter, while the increase in the displacement during the 4th excavation (a maximum of $21 \mathrm{~mm}$ ) was larger than that (a maximum of $5 \mathrm{~mm}$ ) during and after the 3rd excavation. The surface displacement increased up to $1000 \mathrm{~s}$ after the termination of the $3 \mathrm{rd}$

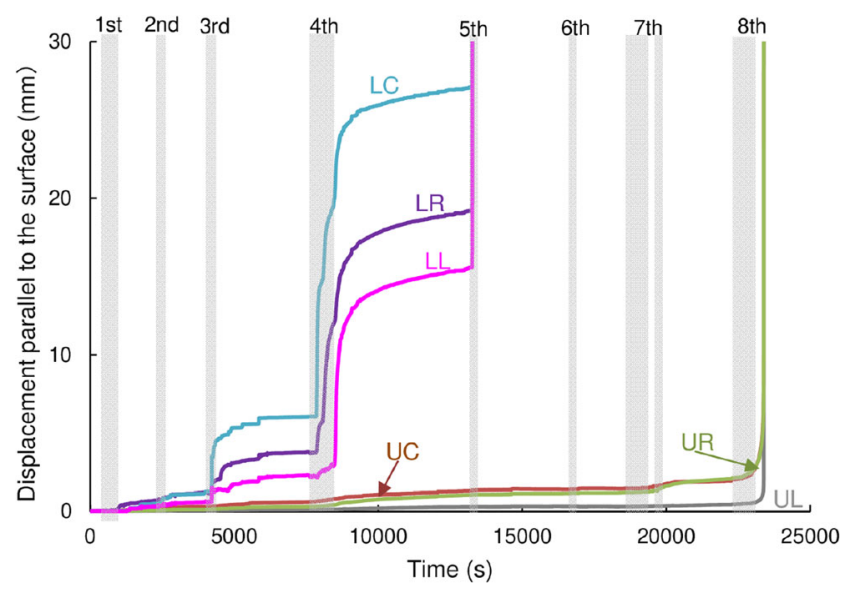

Fig. 7 Time variation of the surface displacement of the model slope

excavation, while it increased for longer than $4000 \mathrm{~s}$ after the termination of the 4th excavation. The excavated face collapsed soon after the start of the 5th excavation, and the surface displacement at the lower part increased substantially. The increase in the surface displacement at the LC was larger than that at the LL and LR positions. This might suggest that the lubrication between the model and the wall provided by the vinyl sheet along the model boundary was not enough to mitigate the friction.

The surface displacements at UC and UR started to increase slightly during the 4 th excavation, and they slowly increased until the 5 th evacuation. The surface displacements at the upper part of the slope did not increase during the 5th excavation when the excavated face below the lower part of the slope collapsed. This result suggested that only a certain part behind the excavated face had become destabilized by the 5th excavation. The surface displacements at the UC and UR locations started to increase again during the latter half of the 7th excavation, while they only slightly increased at the UL during the 7 th excavation. The surface displacement started to greatly increase after the 8th excavation and then showed an accelerated increase until the final slope failure at the upper part of the slope. The amount of surface displacement at UC was almost the same as that at the UL and UR positions. This might indicate that the friction between the model and wall did not greatly influence the lateral slope deformation.

The increases in the surface displacements after the $3 \mathrm{rd}$ and 4th excavations at the lower part and after the 8th excavation at the upper part of the slope occurred due to creep deformation under constant-stress conditions in the slope. They also occurred due to creep deformation during the 5th excavation at the lower part of the slope, but no increases could be observed in Fig. 7 because the duration from the start of excavation to the failure was too short. The rate of increase of the surface displacement over time was high initially and then gradually decreased after the 3rd and 4th excavations at the lower slope, while it exhibited an accelerated increase until 
failure after the 8th excavation at the upper slope. The time variation of the surface displacement rate when the surface displacement almost stabilized after the 3rd and 4th excavations at the lower slope was inverse to that when the surface displacement increased to failure after the 8th excavation at the upper slope.

\section{Velocity and acceleration}

\section{Velocity and acceleration}

The time variation of the velocity until slope failure occurred at the LC position is shown in Fig. 8. The velocity remained very small until the start of the 3rd excavation and then increased during the $3 \mathrm{rd}$, 4th and 5th excavations. The velocity decreased after the termination of these excavations. The time variation during and after the $3 \mathrm{rd}$ and 4 th excavations was not smooth but fluctuated over time, while that during the 5 th excavation increased smoothly over time. Figure 9 shows a magnified view of the time variation of the velocity during the 4th excavation at the LC position. The velocity initially increased substantially and gradually decreased until approximately $8000 \mathrm{~s}$. It fluctuated with peaks at $8150 \mathrm{~s}$ and $8500 \mathrm{~s}$ until the end of the excavation. The fluctuation occurred due to the various scales of the increase steps in the surface displacement over time, as shown in Fig. 10. This figure shows the increase in the surface displacement during the 4th excavation at the LC position. The surface displacement greatly increased from 7800 to $7900 \mathrm{~s}$, after which the increase in the surface displacement over time decreased until $8100 \mathrm{~s}$ (the first step). The increase in the surface displacement over time was large from 8100 to $8170 \mathrm{~s}$ and then decreased until $8450 \mathrm{~s}$ (the second step). A small-scale step-like increase in the surface displacement, which resembled a small fluctuation in the

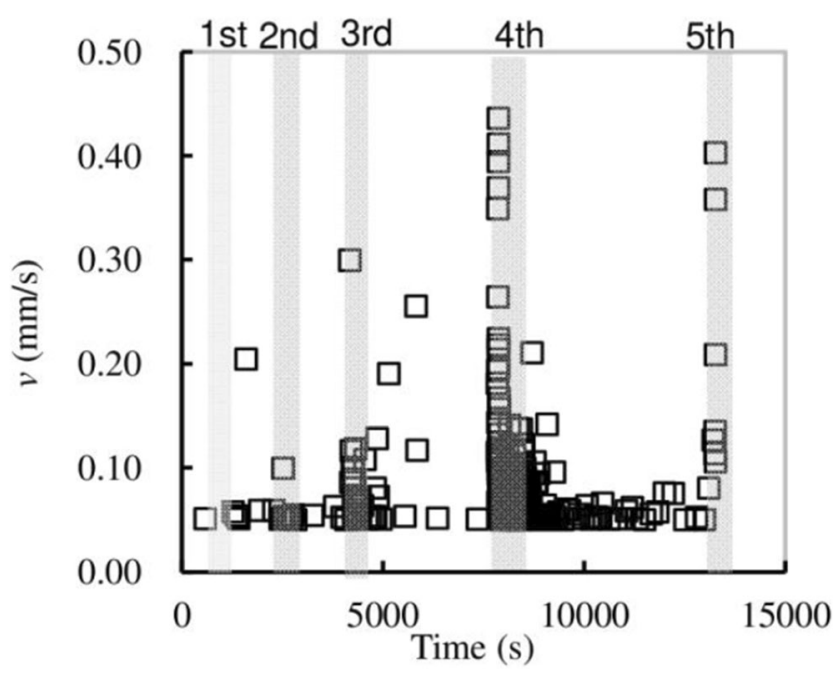

Fig. 8 Time variation of the velocity $(v)$ until failure at the lower centre position

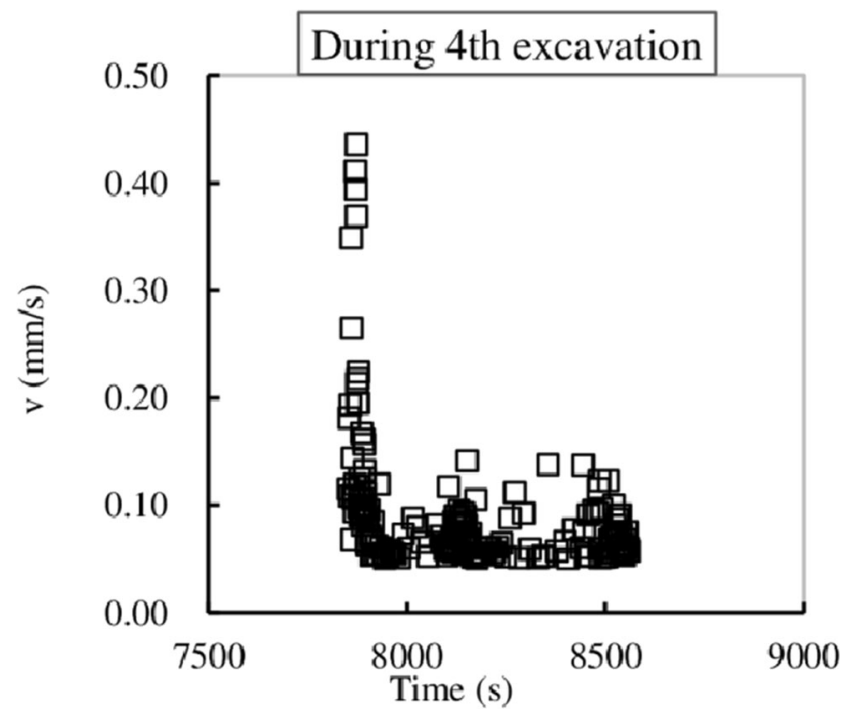

Fig. 9 Time variation of the velocity $(v)$ during the 4 th excavation at the lower centre position

surface displacement over time, was also observed in the figure.

The time variation of the velocity at the UC position until failure occurred is shown in Fig. 11. The velocity was almost $0.05 \mathrm{~mm} / \mathrm{s}$ with small fluctuations until the start of the 8th excavation. It notably increased after the 8th excavation. Small fluctuations may have occurred due to the small-scale step-like increase in the surface displacement.

The time variation of the absolute value of the acceleration until the failure at the LC position is shown in Fig. 12. The positive and negative accelerations represent the increase and decrease in the velocity, respectively. The acceleration varied over magnitudes of $10^{6} \mathrm{~mm} / \mathrm{s}^{2}$. The positive acceleration notably increased initially and then decreased gradually during the 3rd and 4th excavations. The magnitude of the variation

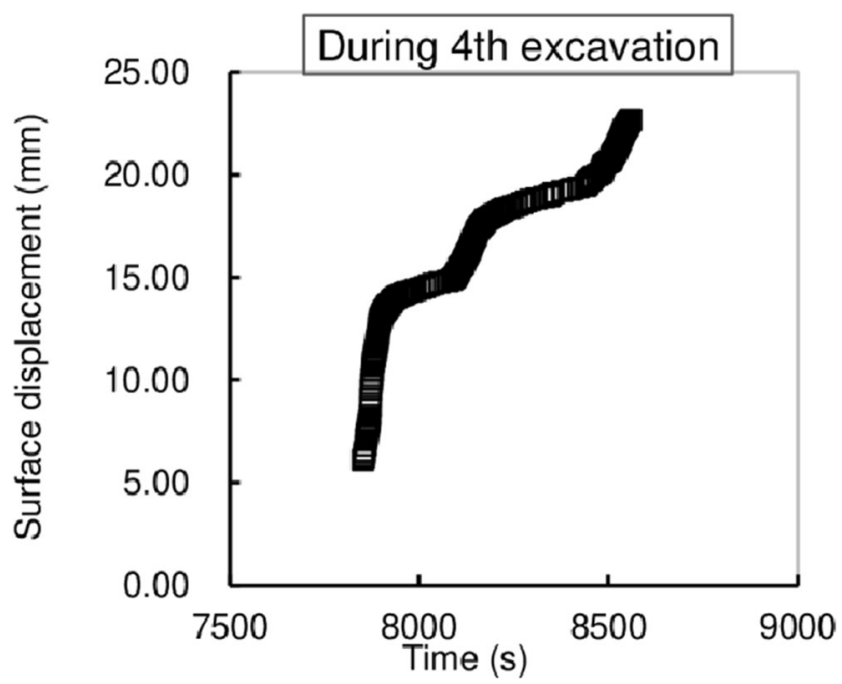

Fig. 10 Time variation of the surface displacement during the 4th excavation at the lower centre position 


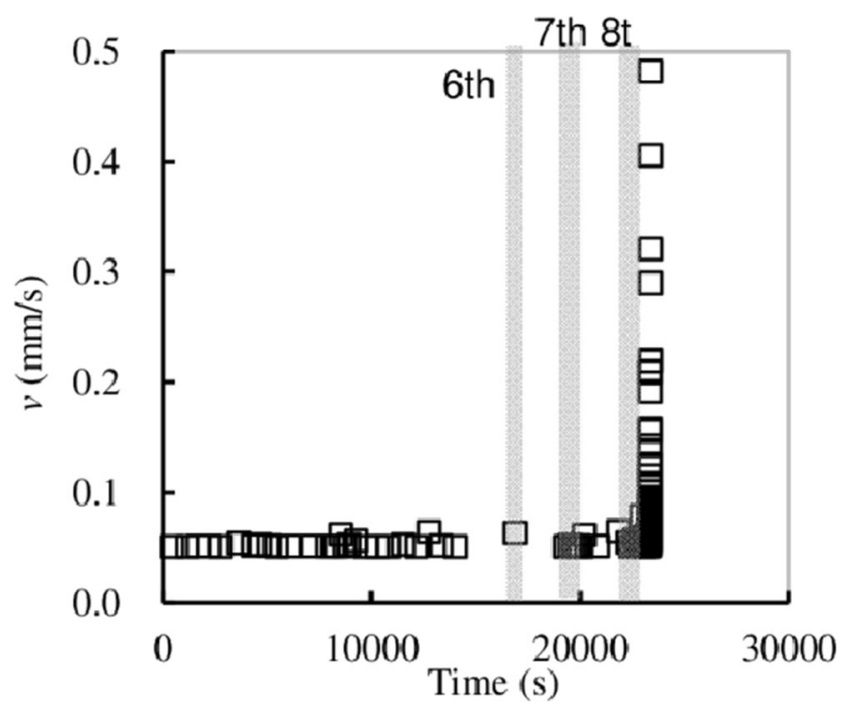

Fig. 11 Time variation of the velocity $(v)$ until failure at the upper centre position

was over $10^{5} \mathrm{~mm} / \mathrm{s}^{2}$ in the increase and decrease of the acceleration. The positive acceleration tended to decrease after the 3 rd and 4th excavations with large fluctuations. It fluctuated over $10^{2} \mathrm{~mm} / \mathrm{s}^{2}$ in neighbouring time steps. It increased monotonically to slope failure during the 5th excavation. The negative acceleration also notably increased initially and then decreased gradually during the 3 rd and 4 th excavations. It monotonically increased during the 5 th excavation. The time variation of the negative acceleration was similar to that of the positive acceleration. This similarity might occur due to the fluctuation in the velocity from a given time step to the next time step, which occurred because of the small-scale step-like increase in the surface displacement.

The time variation of the acceleration until failure was observed at the UC position is shown in Fig. 12. The time variation of the positive acceleration and the absolute value of the negative acceleration are shown in this figure. The acceleration tended to increase slightly until the start of the 8th excavation, with fluctuations ranging from $1 \mathrm{E}-07$ to $1 \mathrm{E}-04 \mathrm{~mm} / \mathrm{s}^{2}$.

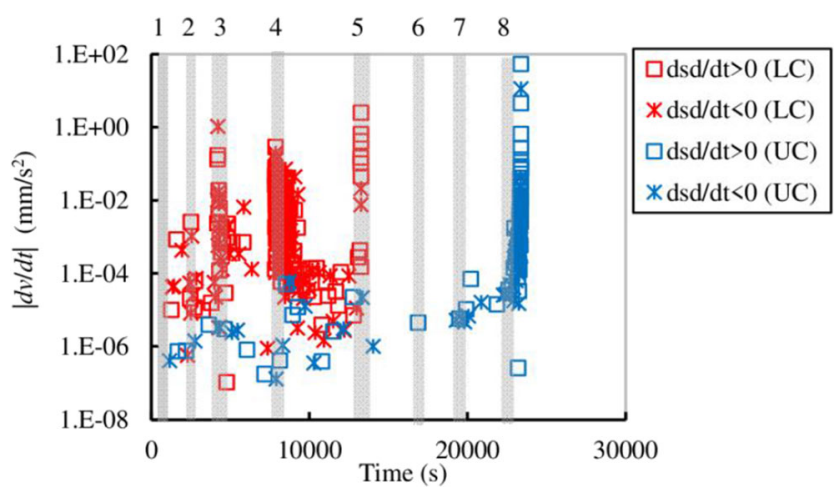

Fig. 12 Time variation of the absolute value of the acceleration $(d v / d t)$ until failure at the lower centre and the upper centre position until failure, with $v$ as the velocity and $d t$ as the time increment. The numbers above the figure indicate the number of the excavation step
The acceleration increased substantially after the 8th excavation. The time variation of the negative acceleration was nearly similar to that of the positive acceleration. This similarity may have occurred due to the fluctuation in the velocity from a given time step to the next time step, which was caused by the small-scale step-like increase in the surface displacement.

\section{Relationship between the velocity and acceleration}

Fukuzono (1985) reported a linear relationship between the velocity and acceleration on a logarithmic scale based on surface displacement measurements in a model slope under constant-intensity water sprinkling. However, the above relationship under slope excavation has not yet been confirmed. Here, the relationship was examined based on the measured data.

It was revealed that not only positive acceleration but also negative acceleration occurred during and after the excavations of the slope. Thus, the relationship between the velocity and negative acceleration should be compared to the relationship between the velocity and positive acceleration. Comparisons of the relationship between the velocity and positive acceleration to that between the velocity and the absolute value of the negative acceleration during and after the 4th excavation at the LC position are shown in Fig. 13a and b, respectively. The horizontal and vertical axes were logarithmic following Fukuzono (1985). The range of the absolute value of the negative acceleration was similar to that of the positive acceleration, while the relationship with the positive acceleration showed a larger velocity than the relationship with the negative acceleration. This suggests that the velocity is larger during the velocity-increasing process than during the velocity-decreasing process. The velocity tended to be constant at a value of $0.05 \mathrm{~mm} / \mathrm{s}$ with different accelerations after the excavation. These findings revealed that the correlation between the velocity and positive acceleration was slightly clearer than that between the velocity and negative acceleration during and after the 4th excavation.

The relationship between the velocity and positive acceleration was adopted hereafter in this paper based on the examination discussed above.

The relationships between the velocity and acceleration at the LR, LC and LL positions are shown in Fig. 14a-c, respectively. The relationship at the LR position was examined according to Fig. 14a. The plots showed little variation until the start of the 3rd excavation because the increase in the surface displacement was very slight. The plots were numerous, especially after the 4 th excavation. The plots before the 5 th excavation gathered around a line extending from $(0.05$, $3.5 \mathrm{E}-7)$ to $(0.143,6 \mathrm{E}-02)$ with a scatter of one order of acceleration. This result suggested that the acceleration fluctuated at the same velocity. The acceleration ranged from 0.003 to $0.1 \mathrm{~mm} / \mathrm{s}^{2}$ at a velocity of $0.1 \mathrm{~mm} / \mathrm{s}$. The relationship followed 


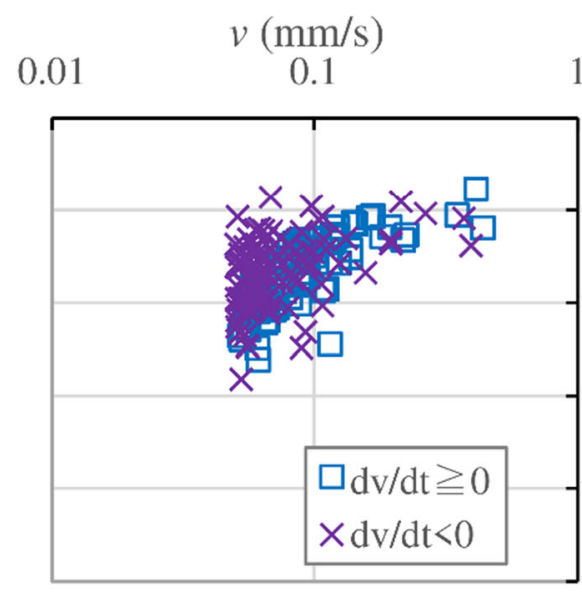

1

$1.0 \mathrm{E}+01$
$1.0 \mathrm{E}-01 \frac{\sqrt[\infty]{5}}{1.0 \mathrm{E}-03}$
$1.0 \mathrm{E}-05 \frac{\Xi}{\frac{\Xi}{\Xi}}$
$1.0 \mathrm{E}-07 \frac{\Xi}{\frac{\Xi}{\Xi}}$
$1.0 \mathrm{E}-09$

(a)
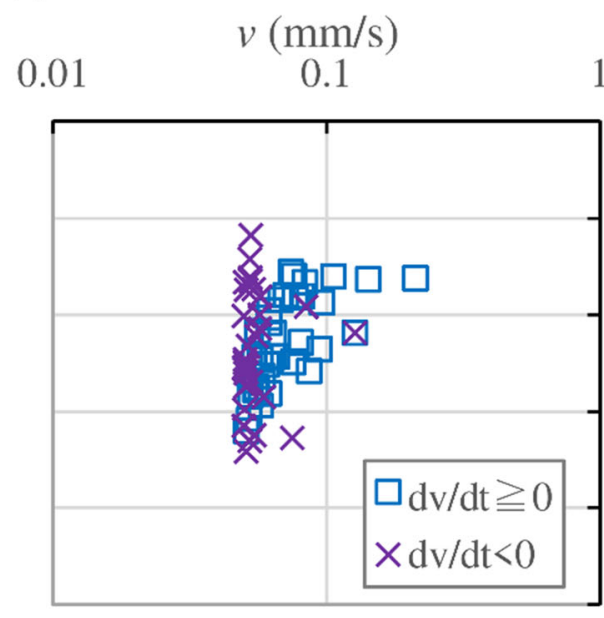

1

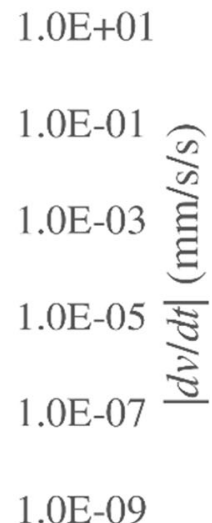

(b)

Fig. 13 Comparison of the relationship between the velocity and acceleration $(d v / d t \geq 0)$ to that between the velocity and absolute value of the acceleration $(d v / d t<0)$ during the 4 th excavation and after the 4 th excavation at the lower centre position, with $v$ as the velocity and $d t$ as the time increment. a During the 4th excavation. b After the 4th excavation

the same tendency until a velocity of $0.143 \mathrm{~mm} / \mathrm{s}$ was reached and then followed a gentler line until slope failure occurred during the 5 th excavation. It should be emphasized that the slope of the trend line changed gradually just prior to the failure. The plots before the 5 th excavation gathered around almost the same line as those at the LR position with a scatter of one order of acceleration at the LC (Fig. 14b) and LL (Fig. 14c) positions. The relationships followed the same tendency until the velocity was approximately $0.1 \mathrm{~mm} / \mathrm{s}$ and $0.143 \mathrm{~mm} / \mathrm{s}$ at the LC and LL positions, respectively, and then followed a more gradually changing line until slope failure occurred during the 5 th excavation at both locations. The relationships at the LC and LL locations were quite similar to those at the LR location.

The relationships between the velocity and acceleration at the lower part of the slope are compared in Fig. 15. The

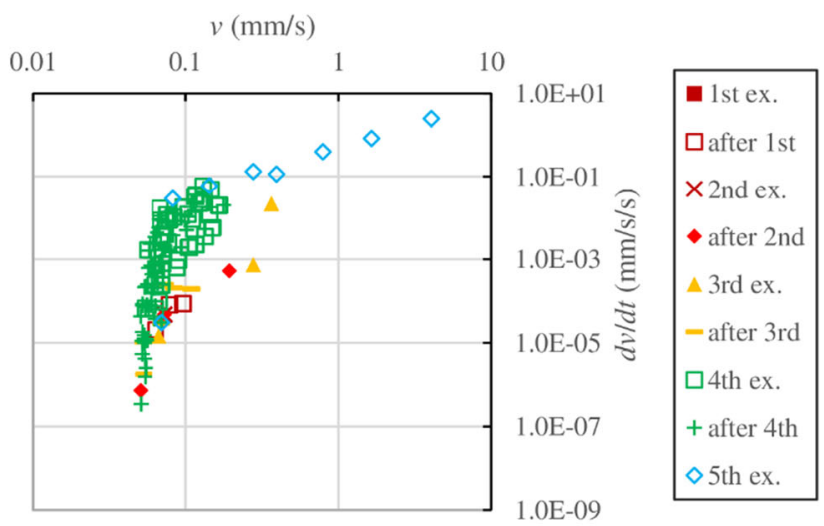

(a)

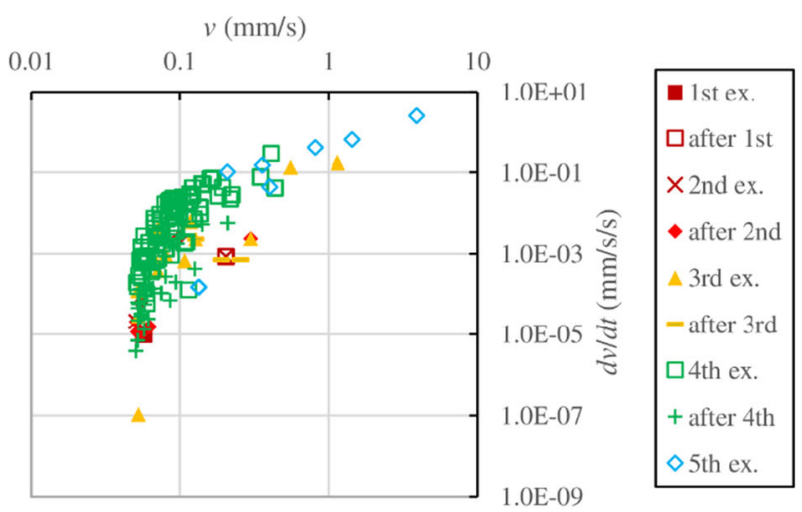

(b)

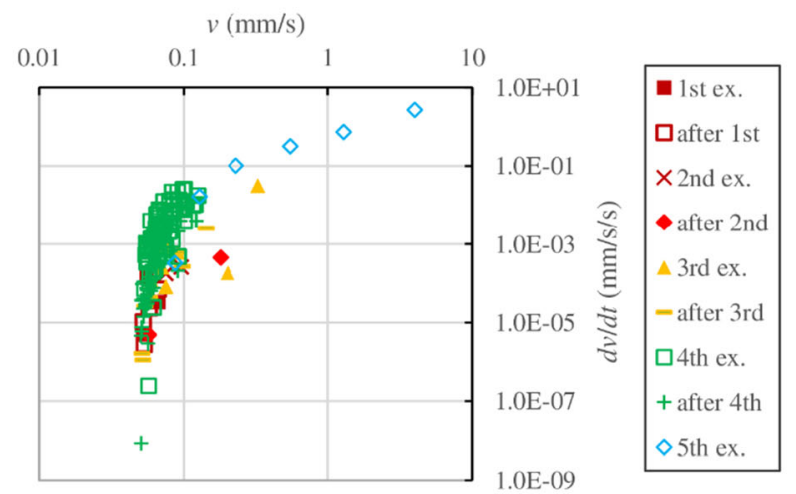

(c)

Fig. 14 Relationships between the velocity and acceleration at the lower right (LR), lower centre (LC) and lower left (LL) positions, with $v$ as the velocity and $d t$ as the time increment. a Lower right. b Lower centre. c Lower left

relationships after the 4th excavation until failure occurred during the 5th excavation are shown at the LR, LC and LL positions in the figure. The plots before the 5 th excavation gathered around a trend line extending from $(0.05,3.5 \mathrm{E}-7)$ to $(0.143,6 \mathrm{E}-02)$ with a scatter of almost 1 order of magnitude of the acceleration at all locations. The relationship followed the same tendency until the velocity reached approximately 


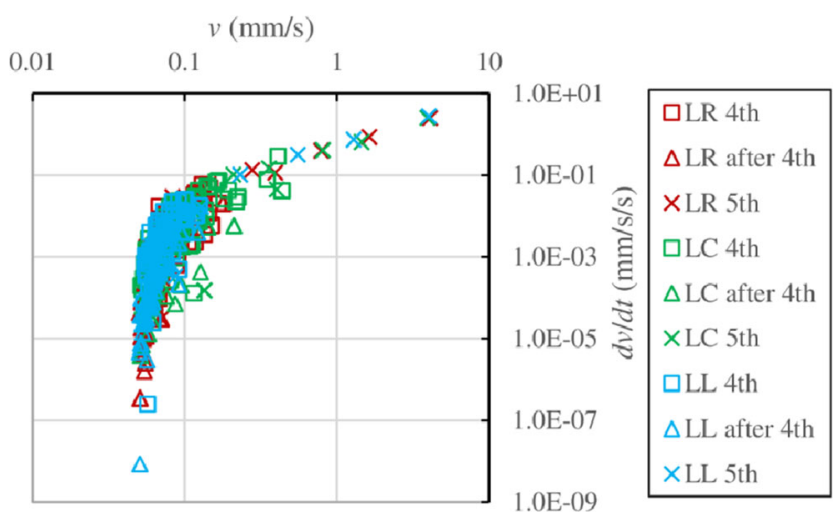

Fig. 15 Comparison of the relationships between the velocity and acceleration from the 4th excavation to the 5th excavation at the lower part of the slope, with $v$ as the velocity and $d t$ as the time increment

$0.14 \mathrm{~mm} / \mathrm{s}$ and then followed a gentler line until failure occurred during the 5 th excavation at all locations. The relationships between the velocity and acceleration after the start of the 8th excavation at the upper part of the slope are compared in Fig. 16. The depicted data points after the start of the 8th excavation were selected because the velocity greatly increased after the start of the 8th excavation at the upper centre location, as shown in Fig. 11. The relationships during the 8th excavation at all locations in the upper part ranged from that at an acceleration of $1 \mathrm{E}-07 \mathrm{~mm} / \mathrm{s}^{2}$ to that at $1 \mathrm{E}-03 \mathrm{~mm} / \mathrm{s}^{2}$ on a line. The relationships after the 8 th excavation at all locations also followed the same line with a small scatter until a velocity of $0.06 \mathrm{~mm} / \mathrm{s}$ was reached, and then followed the curve until a surface displacement velocity of $0.1 \mathrm{~mm} / \mathrm{s}$ was attained with a scatter of an order of the surface displacement acceleration. The relationships at all locations were on the same straight line from a velocity of $0.5 \mathrm{~mm} / \mathrm{s}$ to failure. A comparison of the relationships at the upper part of the slope, as shown in Fig. 16, to those at the lower part of the slope, as shown in Fig. 15, suggested that unique relationships existed at all the locations with some scatter until failure occurred.

The relationships between the velocity and acceleration followed the same trend line, although scatter was

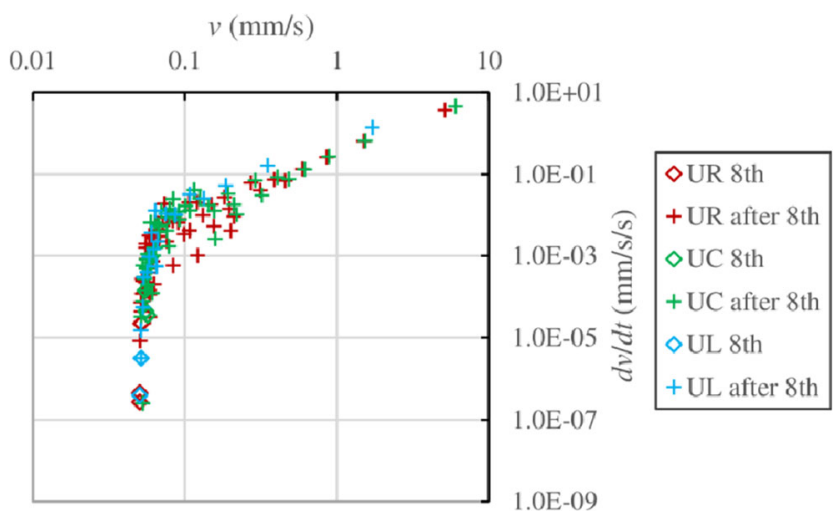

Fig. 16 Comparison of the relationships between the velocity and acceleration from the 8th excavation to final failure at the upper part of the slope, with $v$ as the velocity and $d t$ as the time increment encountered at all locations across the model slope. This suggests that the relationship between the velocity and acceleration might be unique depending on the slope. It should be emphasized that the gradient of the trend line of the relationship suddenly decreased just prior to the slope failure. This might occur due to the change in the mode of the shear deformation of the soil layer in the slope. It is hypothesized that a steep trendline reflects the shear deformation relationship, and a gradual line reflects the relationship just prior to failure of the soil layer.

The relationship is supposed to be affected by the variation of stress ratio in the slope especially during the excavation of the slope because the variation of stress ratio might be large during excavation. Trendline for the relationship might not be linear in this case because of the influence of the variation of stress ratio. Gentler inclination of the trendline for the relationship just prior to failure of the model slope indicates that the relationship depends on the stress ratio in the slope. Scatter of the data might be generated by the nonlinearity of the trendline. But, the influence of the variation of stress condition in the slope could not be examined in this paper. It should be examined in the near future. Thus, a trendline for the relationship is assumed to be linear without the influence of the stress.

\section{Prediction of failure time}

The influence of the inclination of the trendline of the relationship between the velocity and acceleration on the predicted failure time is examined in this chapter.

Novel prediction method was proposed based on the regression analysis for the relationship between the velocity and acceleration at the lower centre and the upper centre of the model slope. First, linear regression analyses were conducted to find the trend of the relationships between the logarithm of velocity and that of acceleration at the lower centre for two different durations: until the start of the 5th excavation (denoted duration 1 hereinafter) and after the start of the 5th excavation (denoted duration 2 hereinafter), as shown in Fig. 17. Then, linear regression analyses were conducted to find the relationships between the velocity and acceleration at the upper centre for two different durations: until the end of the 8th excavation (denoted duration 3 hereinafter) and after the end of the 8th excavation (denoted duration 4 hereinafter), as shown in Fig. 18. These analyses determined the constants $a$ and $\alpha$ in Eq. (1), which are shown in Table 3. As explained in the previous chapter, the inclination of the linear regression line for duration 2 (just prior to the failure of the slope) was smaller than that for duration 1, as shown in Fig. 17 and Table 3. However, there was not a substantial difference between the inclination of the former and that of the latter. The inclination of the linear regression line for duration 3 was much greater than that for duration 4 (just prior to slope 
Table 3 Constants $a$ and $\alpha$ derived from the linear regression analyses in Figs. 17 and 18

\begin{tabular}{lllll}
\hline & $a$ & $\alpha$ & $R^{2}$ & Location \\
\hline Duration 1 & 0.5973 & 3.255 & 0.43 & Lower centre \\
Duration 2 & -0.4843 & 2.1911 & 0.667 & Lower centre \\
Duration 3 & 12.76 & 14.29 & 0.422 & Upper centre \\
Duration 4 & -0.629 & 2.102 & 0.2835 & Upper centre \\
\hline
\end{tabular}

failure), as shown in Fig. 18 and Table 3. Figure 7 shows that the increase in the surface displacement at the lower centre in duration 1 was larger than that in duration 2. This indicates that the stress condition at the end of duration 1 might have been close to causing slope failure. The relationships for duration 1 distributed at almost the same area with that for duration 2 at higher velocities, as shown in Fig. 17. The stress condition at the end of duration 1 might be close to that in duration 2. The surface displacement at the upper centre in duration 3 was much smaller than that in duration 4 , as shown in Fig. 7. This indicates that the stress condition at the end of duration 3 might have been far from causing slope failure. The relationships for duration 4 were on the same trend with the distribution of the relationships for duration 3 until the velocity reached approximately $10^{-1} \mathrm{~mm} / \mathrm{s}$, after which they were on the linear regression line for duration 4 with gentler inclination than for duration 3 . This suggests that the stress condition in duration 3 and the stress condition in duration 4 prior to reaching a velocity of approximately $10^{-1} \mathrm{~mm} / \mathrm{s}$ were far from causing slope failure. However, in duration 4 , the stress condition came close to causing slope failure after reaching a velocity of approximately $10^{-1} \mathrm{~mm} / \mathrm{s}$.

The failure time could be derived from the constants $a$ and $\alpha$ using Eq. (3), as shown in Fig. 19 and Fig. 20. Figure 19 shows a comparison of the relationships between time and the inverse velocity $(1 / v)$ at the start of 5 th excavation in the lower centre for the measured data and those relationships determined using Eq. (3) with constants $a$ and $\alpha$ derived from the data in duration 1 and duration 2. It is assumed that the initial time and $(1 / v)$ in the relationships determined with Eq. (3) are at the start of 5th excavation. The relationship derived using the data in duration 1 predicts an earlier failure time than that derived using the data in duration 2 because of the higher value of $\alpha$ in duration 1 (Table 3). The failure time predicted by the relationship derived using the data in duration 1 is smaller than the measured failure time. However, it is also closer to the measured failure time than the failure time predicted by the relationship derived using the data in duration 2 . This provides a safer prediction of the failure time of the slope. Hence, the failure time could be predicted well with the data in an earlier stage than just prior to failure at the lower centre. Figure 20 shows a comparison of the $v(\mathrm{~mm} / \mathrm{s})$

$\begin{array}{lllll}10^{-2} & 10^{-1} & 1 & 10^{1} & 10^{2}\end{array}$

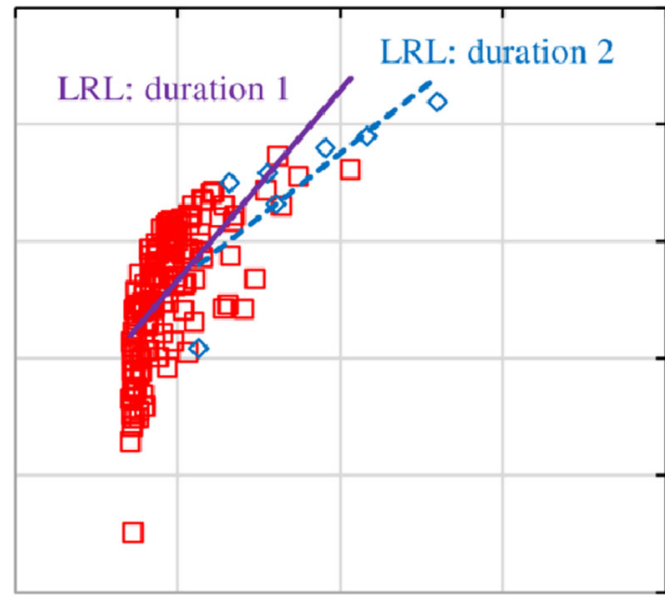

$10^{2}$

$10^{-2}$

है

$\square \quad$ Duration 1 (until the start of the 5th ex.)

$\diamond$ Duration 2 (after the start of the 5th ex.)

Fig. 17 Linear regression analysis for the relationship between the velocity $(v)$ and acceleration $(d v / d t)$ at the lower centre in duration 1 (until the start of the 5th excavation) and duration 2 (after the start of the 5 th excavation). LRL indicates linear regression line

relationships between time and the inverse velocity $(1 / v)$ at the end of 8th excavation in the upper centre for the measured data and those relationships determined using Eq. (3) with

$$
v(\mathrm{~mm} / \mathrm{s})
$$

$\begin{array}{lllll}10^{-2} & 10^{-1} & 1 & 10^{1} & 10^{2}\end{array}$

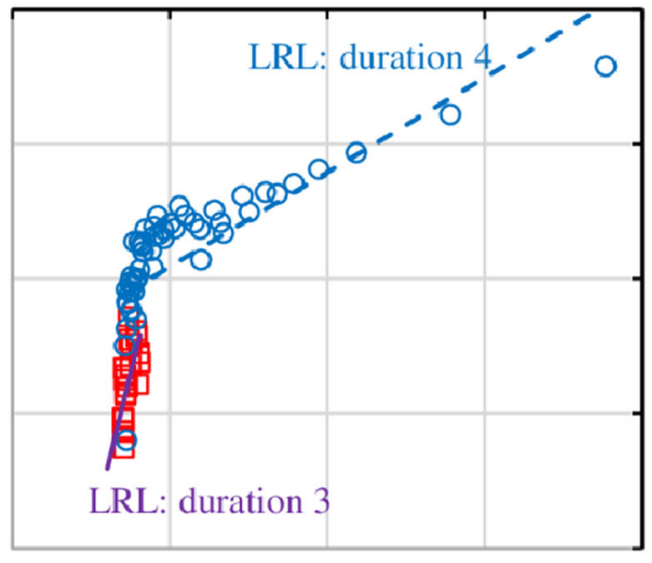

1

$\square \quad$ Duration 3 (until the end of the 8th ex.) O Duration 4 (after the end of the 8th ex.)

Fig. 18 Linear regression analysis for the relationship between the velocity and acceleration at the upper centre in duration 3 (until the end of the 8th excavation) and duration 4 (after the end of the 8th excavation). LRL indicates linear regression line 


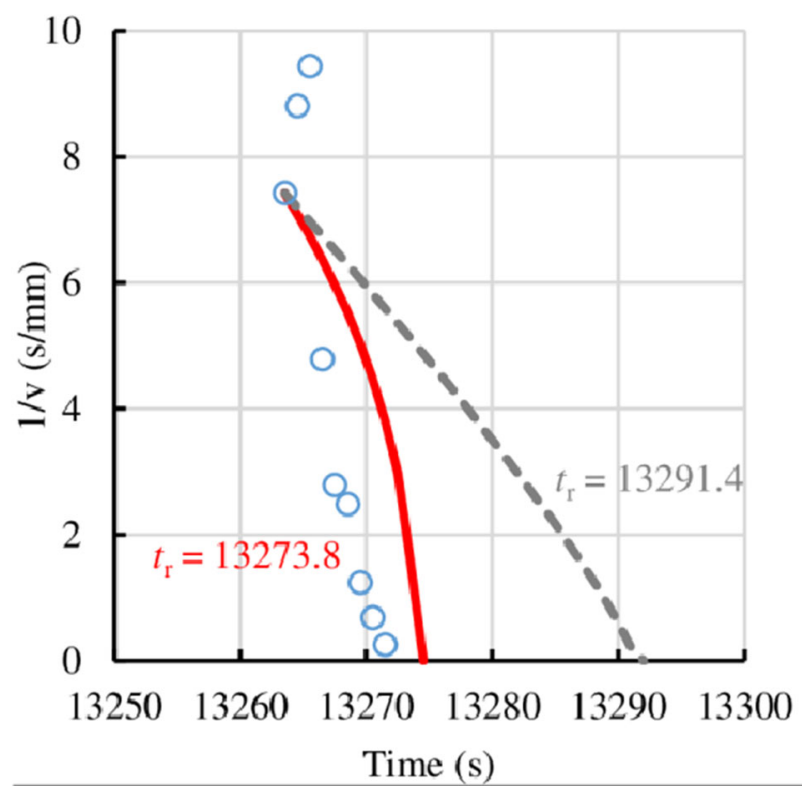

\begin{tabular}{|cc|}
\hline Measred data \\
- Duration 1 & (until the start of the 5th ex.) \\
$-\infty-$ Duration 2 & (after the start of the 5th ex.)
\end{tabular}

Fig. 19 Comparison of the relationship between time and the inverse velocity $(1 / v)$ after the start of 5 th excavation at the lower centre for the measured data and those relationships determined using Eq. (3) with constants $a$ and $\alpha$ derived from the data in duration 1 and duration 2
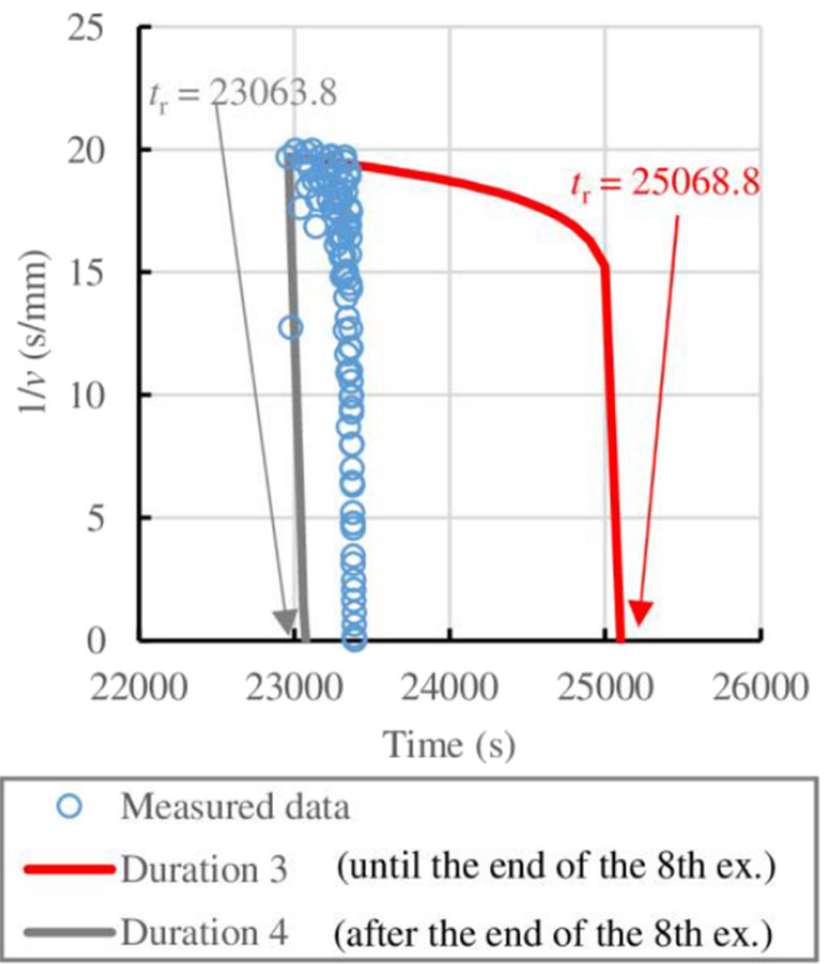

Fig. 20 Comparison of the relationship between time and the inverse velocity $(1 / v)$ after the end of 8th excavation at the upper centre for the measured data and those relationships determined using Eq. (3) with constants $a$ and $\alpha$ derived from the data in duration 3 and duration 4 constants $a$ and $\alpha$ derived from the data in duration 3 and duration 4 . The initial values of the time and inverse velocity in the relationships with constants $a$ and $\alpha$ derived from the data in duration 3 and duration 4 are assumed to be at the end of 8 th excavation. The relationship derived using the data in duration 4 predicts an earlier failure time than that derived using the data in duration 3. However, the predicted failure time with constants $a$ and $\alpha$ derived from the data in duration 3 is much longer than the measured failure time. This is contrary to the results at the lower centre. The constant $a$ is much smaller and $\alpha$ is much larger for the data in duration 3 than those for the data in duration 4. It is recognized that the inclination of the trendline for the relationship derived using the data in duration 3 is much steeper than that of the trendline for the relationship derived using the data in duration 4 . Figure 7 shows that the surface displacement at the upper centre in duration 3 is much smaller than that in duration 4. It is speculated that the stress condition in duration 3 was far from causing slope failure, which resulted in a steep trendline for the relationship between the velocity and acceleration at the upper centre in duration 3 . The surface displacement at the lower centre in duration 1 is larger than that in duration 2 . The stress condition at the end of duration 1 might have been close to the causing slope failure at the lower centre. This fact suggests that failure time predicted using the data from a duration with small displacement might not be able to produce good results because it is far from the failure conditions.

\section{Conclusion}

Multistep excavations at the toe of a large-scale slope model constructed of loamy soil were implemented to measure the slope surface displacement, and the measured surface displacement data were analysed. The following findings were obtained from the analysis:

(1) > The surface displacements at the lower part of the slope showed little variation before the 3rd excavation. However, they greatly increased not only during the 3rd to 5th excavations but also after the 3rd to 4th excavations. The surface displacements at the upper part varied little before the 8th excavation. They started to increase during the 8th excavation and then notably increased thereafter. The surface displacements increased not only during excavation but also thereafter. The displacement increase after the excavation was due to creep deformation under a constant stress in the slope.

(2) The surface displacements did not increase monotonically, while they increased with small fluctuations even prior to failure. The small fluctuations may have been due to the small-scale step-like increase in the surface displacement. The time variation of the velocity and acceleration 
fluctuated greatly when the surface displacement notably increased. The value of the acceleration was not only positive but also negative with the same magnitude as the positive acceleration due to the fluctuation of the velocity.

(3) The relationships between the velocity and acceleration followed the same trend line and was linear on logarithmic scale although with small scatter at all locations in the model slope, as reported in many studies for rainfall-induced landslides and the creep failure of slopes. This result suggests that the relationship between the velocity and acceleration was unique depending on the slope. The gradient of the trend line of the relationship suddenly decreased just prior to failure. These facts suggest that the relationship might be nonlinear between the period of large deformation and prior to failure.

(4) Steeper trendline with the data at large deformation stage produces earlier failure time predicted on the relationship between the velocity and acceleration if the displacement is large and close to failure in the slope. It is safer than the prediction based on measured data. Steeper trendline at large deformation stage produces bad result for predicting failure time if the displacement is small and far from failure of the slope. Predicted failure time based on the measured data or the data just prior to failure is closer to actual failure time in this case.

The influence of stress change to the relationship between the velocity and acceleration and basic idea for the location of displacement sensors on the slope should be examined in the near future for the practical use of the prediction method of failure time based on the measurement of the displacement.

Funding Part of this study was financially supported by the Grant-in-Aid for Challenging Exploratory Research, 16K12855, JSPS.

\section{Declarations}

Competing interests The authors declare no competing interests.

Open Access This article is licensed under a Creative Commons Attribution 4.0 International License, which permits use, sharing, adaptation, distribution and reproduction in any medium or format, as long as you give appropriate credit to the original author(s) and the source, provide a link to the Creative Commons licence, and indicate if changes were made. The images or other third party material in this article are included in the article's Creative Commons licence, unless indicated otherwise in a credit line to the material. If material is not included in the article's Creative Commons licence and your intended use is not permitted by statutory regulation or exceeds the permitted use, you will need to obtain permission directly from the copyright holder. To view a copy of this licence, visit http://creativecommons.org/licenses/by/4.0/.

\section{References}

Askarinejad A, Akca D, Springman SM (2018) Precursors of instability in a natural slope due to rainfall: a full-scale experiment. Landslides $15: 1745-1759$

Bozzano F, Cipriani I, Mazzanti P, Prestininzi A (2011) Displacement patterns of a landslides affected by human activities: insights from ground-based InSAR monitoring. Nat Hazards 59:1377-1396

Carlà T, Fanina P, Intrieri E, Botsialas K, Casagli N (2017) On the monitoring and early-warning of brittle slope failures in hard rock masses: examples from an open-pit mine. Eng Geol 228:71-81

Carlà T, Nolesini T, Solari L, RivoltaC CLD, Casagli N (2019) Rockfall forecasting and risk management along a major transportation corridor in the Alps through ground-based radar interferometry. Landslides 16:1425-1435

Crosta GB, Agliardi F (2003) Failure forecast for large rock slides by surface displacement measurements. Can Geotech J 40:176-190

Federico A, Popescu M, Elia G, Fidelibus C, Interno G, Murianni A (2012) Prediction of time to slope failure: a general framework. Environ Earth Sci 66(1):245-256

Fukuzono T (1985) A new method for predicting the failure time of a slope. Proc. IVth Intern. Conf. and Field Workshop on Landslides, Tokyo, pp 145-150

Hao S, Liu C, Lu C, Elsworth D (2016) A relation to predict the failure of materials and potential application to volcanic eruptions and landslides. Sci Rep 6:27877. https://doi.org/10.1038/srep27877

Hao S, Yang H, Elsworth D (2017) An accelerating precursor to predict "time to failure" in creep and volcanic eruptions. J Volcanol Geotherm Res 343:252-262

Kromer RA, Huchinson DJ, Lato MJ, Gautheir D, Edwards T (2015) Identifying rock slope failure precursors using LiDAR for transportation corridor hazard management. Eng Geol 195:93-103

Loew S, Gschwind S, Gishig V, Keller-Signer A, Valenti G (2017) Monitoring and early warning of the 2012 Preonzo catastrophic rock slope failure. Landslides 14:141-154. https://doi.org/10.1007/ s10346-016-0701-y

Mazzanti P, Bozzano F, Cipriani I, Prestininzi A (2015) New insights into the temporal prediction of landslides by a terrestrial SAR interferometry monitoring case study. Landslides $12: 55-58$

Rigby RJ, Carr RJ (1987) Monitored failure of an excavation in an ancient landslide within the Newcastle coal measures. In: Walker F (ed) Soil slope instability and stabilization. Balkema, Rotterdam, pp $397-402$

Saito M (1965) Forecasting the time of occurrence of a slope failure. Proc 6th Intern Conf on Soil Mech and Foundation Eng Montreal, Canada 2:537-541

Saito M, Yamada G (1973) Forecasting and result in case of landslide at Takabayama. Proc 8th Intern Conf on Soil Mech and Foundation Eng, Moscow, USSR 4(3):325-327

Tamate S, Hori T (2018) Monitoring shear strain in shallow subsurface using mini pipe strain meter for detecting potential threat of slope failure. Geotech Test J 41(2):413-424

Varns DJ (1982) Time-deformation relations in creep to failure of earth materials. Proc of 7th Southeast Asian Geotechnical Conference 2: $107-130$

Voight B (1988) A relation to describe rate-dependent material failure. Science 243:200-203

Voight B (1989) Materials science law applies to time forecasts of slope failure. Japan Landslide Society (Eds.), Landslide news 3, Tokyo, pp 8-10

Voight B, Kennedy BA (1979) Slope failure of 1967-1969, Chuquicamata mine, Chile. In: Voight B (ed) Rockslides and avalanches 2, engineering sites. Elsevier, Amsterdam, pp 595632 
Xiao JQ, Ding DX, Xu G, Jiang FL (2009) Inverted S-shaped model for nonlinear fatigue in rock. Int J Rock Mech Min Sci 46:643-548

Xie J, Uchimura T, Wang G, Shen Q, Maqsood Z, Xie C, Liu J, Lei W, Tao S, Chen P, Dong H, Mei G, Qiao S (2020) A new prediction method for the occurrence of landslides based on the time history of tilting of the slope surface. Landslides 17:301-312. https://doi.org/ 10.1007/s10346-019-01283-8
Zhou XP, Ye T (2021) Inverse-square-root-acceleration method for predicting the failure time of landslides. Sci China Technol Sci 2021:64. https://doi.org/10.1007/s11431-020-1722-2

Zhou XP, Liu LJ, Xu C (2020) A modified inverse-velocity method for predicting the failure time of landslides. Eng Geol 268(2020: 105521. https://doi.org/10.1016/j.enggeo.2020.105521 